\title{
Use of Entomopathogenic Nematodes for Control of Grape Phylloxera (Homoptera: Phylloxeridae): A Laboratory Evaluation
}

\author{
GREG ENGLISH-LOEB, MIKE VILLANI, TIM MARTINSON, ANNA FORSLINE, \\ AND NANCY CONSOLIE
}

Department of Entomology, Cornell University, New York State Agricultural Experiment Station, Geneva, NY 14456

\begin{abstract}
Environ. Entomol. 28(5): 890-894 (1999)
ABSTRACT The effectiveness of 2 species of entomopathogenic nematodes was examined in the laboratory against the root-form of grape phylloxera Daktulosphaira vitifolia (Fitch). Our basic unit of measurement was survival of grape phylloxera established on root pieces of the cultivated grape Vitis vinifera L. variety 'Cabernet Sauvignon' in the presence or absence of nematodes. In petri dish trials, the Oswego strain of Heterorhabditis bacteriophora Poinar reduced survival of attached grape phylloxera by up to $80 \%$ relative to the control treatment, whereas Steinernema glaseri Steiner (isolate 326) had no measurable impact and was not used in further experiments. Hb Oswego significantly reduced survival of grape phylloxera on root pieces placed in small cups filled with soil, but only when soil moisture was high ( $>13 \%$ water content wt:wt) and when high densities of infective nematodes were used (>15,000/g soil). Grape phylloxera exposed to Hb Oswego often turned a brick-red color, indicating successful infection. However, we did not detect any evidence that $\mathrm{Hb}$ Oswego could successfully reproduce within the bodies of grape phylloxera hosts. Therefore, although Hb Oswego can exert significant mortality in the laboratory, their use in the field in an augmentative release program may be constrained by the need to use high densities, their dependence on moist soils, and their inability to propagate themselves within grape phylloxera hosts.
\end{abstract}

KEY WORDS Daktulosphaira vitifolia, Vitis, phylloxera, entomopathogenic nematodes, biological control, soil moisture

GraPe PHYLlOXera, Daktulosphaira vitifolia (Fitch), is a major pest of grapes and has had a profound impact on viticultural practices world-wide (Winkler et al. 1974). Cultivars of Vitis vinifera L. are particularly susceptible to the root-form of grape phylloxera and it is generally necessary to grow these varieties on resistant rootstock wherever grape phylloxera has become well established. Insecticides have generally not been successful in preventing the decline of vine health in vineyards with well-established grape phylloxera populations (Weber et al. 1996). Fortunately, the use of resistant rootstocks has proven to be an effective approach to managing this pest. There are potential problems, however, with reliance on resistant rootstocks. First, biotypes of grape phylloxera have emerged in many parts of the world that are capable of sustaining high populations on formerly resistant rootstocks (Granett et al. 1985, King and Rilling 1985, Song and Granett 1990, De Benedictis and Granett 1992). Second, there is considerable expense associated with the use of grafted vines. For these and other reasons it would be desirable to have alternative control methods available for root-form phylloxera.

Surprisingly little is known about the interaction of the root-form of grape phylloxera and natural enemies. In his pioneering work on grape phylloxera in the northeast, Riley (1874) reported predation by syrphid fly larvae and mites. His initial observations have not been verified. As mentioned previously, cultivars of $V$. vinifera are very susceptible to attack by root-form phylloxera and are generally killed within a few years. In New York, where grape phylloxera are indigenous, however, there are several cases in which $V$. vinifera vines have survived for $>20 \mathrm{yr}$ (Robert Pool, Viticulturist, Cornell University, Geneva, NY, unpublished data). A number of factors could contribute to this result. One hypothesis is that phylloxera in New York are less virulent against V. vinifera grapevines than strains introduced to California or other areas outside the natural distribution of grape phylloxera (Fergusson-Kolmes and Dennehy 1993). Natural enemies as well as different climatic conditions may play important roles in extending the survival of $V$. vinifera in New York. We currently cannot adequately distinguish among competing hypotheses, although Riley's initial observations are encouraging.

In recent years, there has been renewed interest in controlling soil insect populations with entomopathogenic nematodes (Kaya and Gaugler 1993). Entomopathogenic nematodes Heterorhabditis and Steinernema spp. are in current use, or being considered for use, as commercial control agents against soil insects in many agricultural and horticultural systems (Gaugler and Kaya 1990, Kaya 1990, Georgis and Gaugler 1991, Kaya and Gaugler 1993). The results from these efforts, however, have been variable, presumably be- 
cause factors that prohibit or interfere with pathogen epizootics in the soil (e.g., edaphic environmental factors and insect/pathogen interactions) have not been clearly understood nor adequately addressed (Villani and Wright 1990, Georgis and Gaugler 1991, Schroeder et al. 1993).

In this study, we conducted initial laboratory experiments to assess the potential of entomopathogenic nematodes as biological control agents against the root-form of graph phylloxera. Our 4 specific objectives were as follows: (1) to quantify the impact of 2 species of entomopathogenic nematodes on grape phylloxera survival under optimal petri dish conditions in the absence of soil, (2) quantify the influence of soil moisture content on interactions between phylloxera and entomopathogenic nematodes, (3) estimate the dose-response relationship between the best performing nematode and grape phylloxera, and (4) determine whether entomopathogenic nematodes can successfully reproduce within adult phylloxera.

\section{Materials and Methods}

Phylloxera Colony Maintenance and Protocols for Bioassays. This research was carried out at the New York State Agricultural Experiment Station in Geneva from the fall of 1996 through the spring of 1997. Grape phylloxera were originally collected from galls present on the leaves of riverbank grape Vitis riparia Michx. growing in the vicinity of Geneva, NY, and then maintained in the laboratory on root pieces of $V$. vinifera cultivar 'Cabernet Sauvignon' following procedures outlined by De Benedictis and Granett (1992). Cabernet Sauvignon root pieces used in colony maintenance and for bioassays were initially obtained from a vineyard in eastern Washington State free of phylloxera and thereafter stored in a cold room in wet sawdust.

Grape phylloxera used in bioassays (see below) were established using similar initial procedures. Each sample unit was a fresh piece of Cabernet Sauvignon root $\approx 5-7 \mathrm{~cm}$ long and 4-6 $\mathrm{mm}$ in diameter, wrapped with wet cotton around one end. Approximately 100 phylloxera eggs from our laboratory colony were moved to each root piece using a fine brush. Typically, $50 \%$ of these eggs would become attached to root pieces. Root pieces were placed on moist paper inside plastic crispers and incubated in a growth chamber at $25^{\circ} \mathrm{C}, 75 \% \mathrm{RH}$, and $24 \mathrm{~h}$ darkness for $\approx 2 \mathrm{wk}$. This time interval was sufficient to allow eggs to hatch and crawlers to become established on root pieces. We counted all attached phylloxera on a root piece using a dissecting scope before applying treatments. We used survival of attached phylloxera over the subsequent 7-14 $\mathrm{d}$ to assess the impact of nematodes where survival is defined as ( [ number alive at time $t /$ number alive at precount $] \times 100)$.

Nematodes used in these experiments were reared in the laboratory of M.V. using greater wax moth larvae, Galleria mellonella L., following procedures outlined by Woodring and Kaya (1988).
Impact of Entomopathogenic Nematodes: Petri Dish Trials. We conducted 2 separate petri dish experiments to initially screen the potential of 2 species of entomopathic nematodes, Heterorhabditis bacteriophora Poinar (Oswego strain) and Steinernema glaseri Steiner (isolate 326), as control agents for grape phylloxera. In the 1st experiment, root pieces plus phylloxera were either inoculated with $30,000 \mathrm{H}$. bacteriophora infective juveniles or distilled water only (6 replicates per treatment). The 2 nd experiment was identical to the 1 st, but we also used $S$. glaseri (10 replicates per treatment). Treatments were applied by adding $1 \mathrm{ml}$ of solution directly on a root piece with 3rd- and 4th-instar phylloxera and another $1 \mathrm{ml}$ on a half-piece of filter paper on top of the root $(\approx 15,000$ infective juveniles per milliliter for replicates that received nematodes). This was done to provide a continuous path between the root piece and nematodes. Each root piece was placed in its own petri dish (diameter $=88 \mathrm{~mm}$ ). Covered petri dishes were moved to the growth chamber set at $25^{\circ} \mathrm{C}, 75 \% \mathrm{RH}$, and $24 \mathrm{~h}$ darkness. We counted the number of posttreatment live, dead, and missing phylloxera at days 6,11 , and 14 in experiment 1 and days 6 and 10 in experiment 2. On hosts such as greater wax moth, these 2 species of nematodes require only 5-7 d to complete development and produce infective juveniles (Woodring and Kaya 1988). A student $t$-test was used to test for effect of nematodes in experiment 1 and one-way analysis of variance (ANOVA) was used in experiment 2 (SAS Institute 1995). For petri dish experiments, as well as data from other experiments described below, survival data were square-root arcsine transformed for statistical analyses.

Impact of $\boldsymbol{H}$. bacteriophora on Grape Phylloxera: Soil Moisture Trial. Environmental conditions can have a large impact on efficacy of entomopathogenic nematodes. Soil moisture, in particular, can be of critical importance (Gaugler 1988). In this experiment we tested whether $H$. bacteriophora was capable of killing grape phylloxera on root pieces placed in a soil environment that varied in water content. We used a natural loamy sand soil established at 3 levels of water content (wt:wt); dry-11\%, medium-14\%, and wet-17\% (10 replicates per treatment). Soil was placed in the bottom half of a 59-ml wax-coated paper cup, followed by a root piece colonized with 3rd- and 4th-instar phylloxera. Soil was loosely added until the cup was full. Half the cups received $1 \mathrm{ml}$ of water containing $\approx 15,000$ infective nematodes and the other half received $1 \mathrm{ml}$ of distilled water. The cups were covered with plastic lids and incubated in a growth chamber for $2 \mathrm{wk}$, after which the root pieces were removed and examined. We counted the number of posttreatment live, dead, and missing phylloxera plus eggs, crawlers, and recently attached crawlers. Two-way ANOVA was used to test for the effect of soil moisture, nematodes, and the interaction between these 2 factors on phylloxera survival.

Dose-Response Relationship for $\boldsymbol{H}$. bacteriophora and Phylloxera. We examined the relationship between concentration of infective juvenile $H$. bacterio- 
phora and grape phylloxera survival using root pieces with attached phylloxera placed in a 59-ml wax-coated paper cup and surrounded with sandy loam soil established at a water content of $15 \%$. We applied infective nematodes at 6 levels: $0 ; 3,750 ; 7,500 ; 15,000$; 30,000 ; and 45,000 . There were 10 replicates per treatment. After incubating cups in a growth chamber for $10 \mathrm{~d}$ we removed root pieces and counted the number of live and dead adults, eggs, crawlers, and newly attached immatures. This results were analyzed by regressing the survival of phylloxera against the number of infective nematodes released per cup using simple linear regression (SAS Institute 1995).

Propagation of $\boldsymbol{H}$. bacteriophora within Phylloxera. To determine whether adult grape phylloxera are suitable hosts for reproduction of $H$. bacteriophora we isolated 10 individual phylloxera from root pieces exposed to the high dose of infective nematodes in the dose-response experiment. We preferentially chose dead adults that had maintained their body integrity and had turned a red-black color. Hosts successfully killed by H. bacteriophora typically take on a characteristic red-black color (Kaya and Gaugler 1993). These individuals were placed on plaster of paris blocks, wetted with distilled water, put in a small petri dish (50 $\mathrm{mm}$ diameter), and placed in a dark growth chamber at $25^{\circ} \mathrm{C}$ for $7 \mathrm{~d}$. After this time we examined each individual phylloxera under a dissecting microscope for evidence of infective juveniles.

\section{Results}

Impact of Entomopathogenic Nematodes: Petri Dish Trials. In experiment 1 , survival of phylloxera exposed to H. bacteriophora was reduced by $62 \%$ after $6 \mathrm{~d}$ and $80 \%$ after $10 \mathrm{~d}$ relative to survival of control phylloxera $(t=3.4, \mathrm{df}=10, P=0.007$, $t$-test on data from $10 \mathrm{~d}$ census) (Fig. 1). In experiment 2, H. bacteriophora reduced survivorship by 31,39 , and $55 \%$ after 6,11 , and $14 \mathrm{~d}$, relative to survivorship of control phylloxera (Fig. 2) (contrast between check and $H$. bacteriophora, day $14: F=14.2 ; \mathrm{df}=1,27 ; P<0.001$ ), whereas S. glaseri did not have a significant impact (Fig. 2) (contrast between check and S. glaseri, day 14: $F=0.3 ; \mathrm{df}=1,27 ; P>0.5)$. Phylloxera treated with $H$. bacteriophora often turned a characteristic brickred or black color.

Impact of Entomopathic Nematodes: Soil Moisture Trial. By the end of the soil moisture experiment (14 d), soil water content had dropped by $1-2 \%$ for all levels, but differences among treatments were maintained. Overall, nematodes had a significant, negative influence on survival of phylloxera $(F=5.1$; $\mathrm{df}=1,54$; $P<0.03)$ and soil moisture had a negative influence $(F=5.5 ; \mathrm{df}=2,54 ; P<0.01)$. In addition, there was a marginally significant interaction between nematodes and moisture $(F=2.7 ; \mathrm{df}=2,54 ; P=0.07)$. Thus, there was no effect of nematodes in the dry $(11 \%)$ soil ( single contrast, $F=0.3 ; \mathrm{df}=1,54 ; P=0.6$ ) but there was an effect at the wet $(17 \%)$ soil condition (single contrast, $F=6.4$; $\mathrm{df}=1,54 ; P=0.01$ ) (Fig. 3).

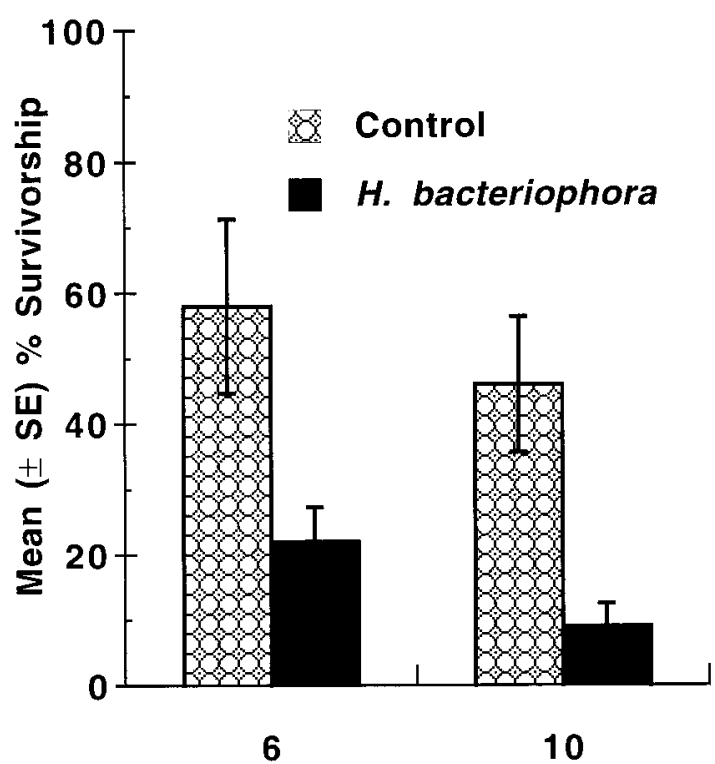

\section{No. Days After Treatment}

Fig. 1. Mean percent survivorship $( \pm \mathrm{SE}$ ) of attached grape phylloxera on Cabernet Sauvignon root pieces placed in petri dishes and treated with either infective juveniles of H. bacteriophora or distilled water.

Dose-Response Relationship for $\boldsymbol{H}$. bacteriophora and Phylloxera. There was a strong negative relationship between survival of phylloxera and dose of in-

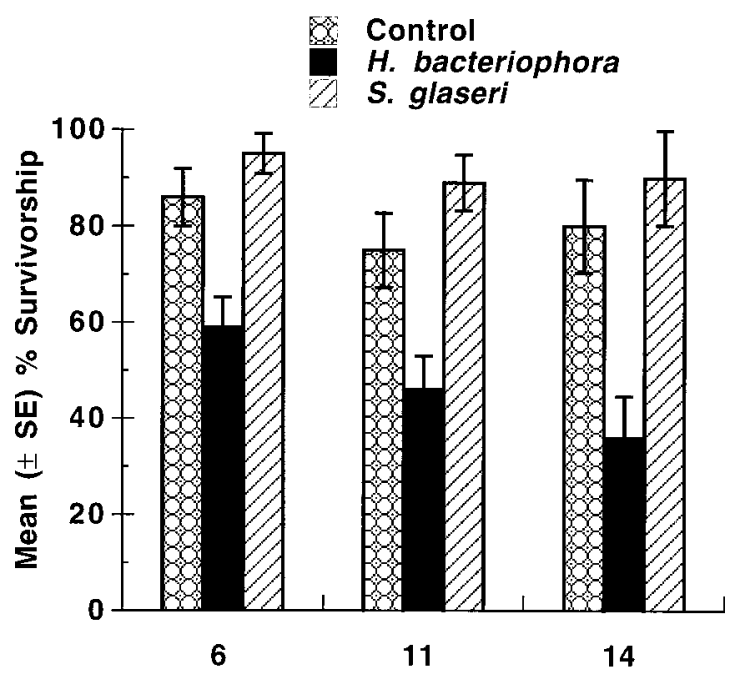

No. Days After Treatment

Fig. 2. Mean percent survivorship ( $\pm \mathrm{SE}$ ) of attached grape phylloxera on Cabernet Sauvignon root pieces placed in petri dishes and treated with infective juveniles of $H$. bacteriophora, infective juveniles of S. glaseri, or distilled water. 


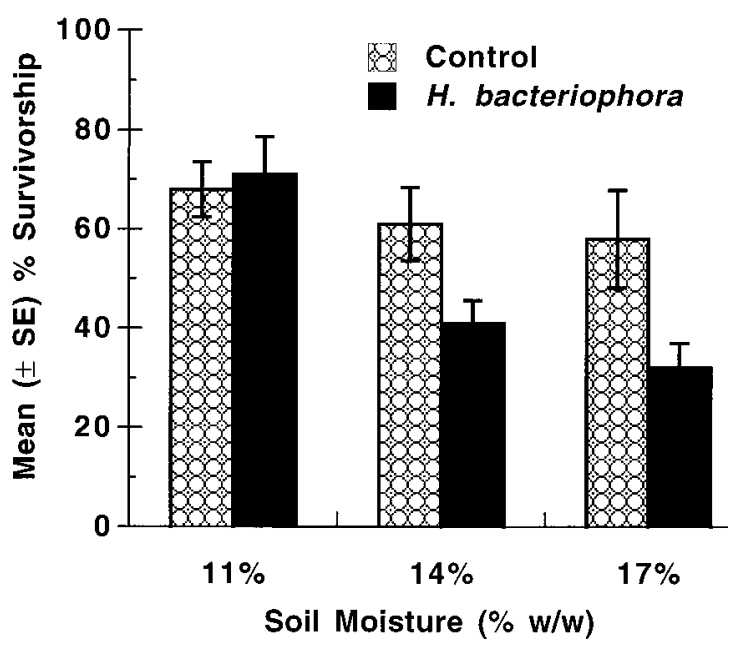

Fig. 3. Mean percent survivorship $( \pm \mathrm{SE})$ of attached grape phylloxera on Cabernet Sauvignon root pieces placed in small cups with soil established at 3 water moisture levels (\% wt:wt) and treated either with infective juveniles of $H$. bacteriophora or distilled water.

fective nematodes $\mathrm{y}=0.965-0.000012 \times[\mathrm{SE}=$ $0.000002] ; F=40.27$;f $\left.=1,58 ; r^{2}=0.40 ; P<0.001\right)$ (Fig. 4). At the lowest dose of 3,750 nematodes, there was a $34 \%$ decrease in survival of phylloxera relative to controls, whereas at an intermediate dose $(15,000$ infective juveniles) we observed a $50 \%$ decline in survival relative to control phylloxera ( $45 \%$ verses $85 \%$ ). At the highest doses, there was a $70 \%$ decline in survival of attached phylloxera relative to the control treatment.

Propagation of $\boldsymbol{H}$. bacteriophora within Phylloxera. We found no evidence that $H$. bacteriophora is capable of reproducing inside a phylloxera host. We did not

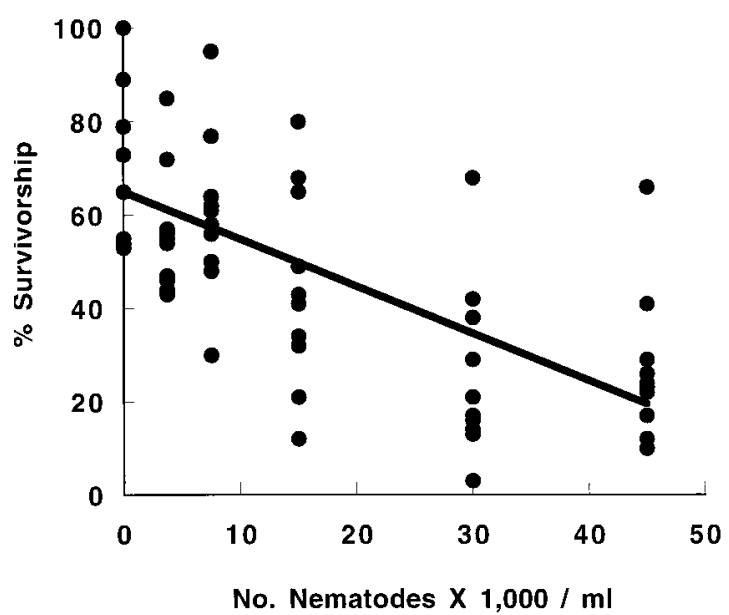

Fig. 4. Mean percent survivorship $( \pm \mathrm{SE}$ ) of attached grape phylloxera on Cabernet Sauvignon root pieces placed in cups with soil and treated with different concentrations of infective juveniles of $H$. bacteriophora. observe any streaming or other evidence of infective juvenile nematodes being produced from isolated phylloxera cadavers incubated under ideal rearing conditions.

\section{Discussion}

In these experiments, we examined the potential use of 2 species of entomopathogenic nematodes as control agents of grape phylloxera under laboratory conditions. In a series of experiments we found that the Oswego strain of $\mathrm{H}$. bacteriophora was capable of reducing survival of attached phylloxera by up to $80 \%$ relative to the control treatment (Fig. 2). For a number of reasons, however, $H$. bacteriphora is unlikely to be a very useful biological control agent for phylloxera using traditional approaches such as augmentative or classical releases. First, despite using extremely high densities of infective nematodes, we never achieved $100 \%$ mortality (Fig. 4). To put things in perspective, field applications of entomopathic nematodes are typically made at rates between 1.2 and 3.7 billion/ha (Villani and Wright 1988). In our dose-response experiment, our lowest concentration was equivalent to close to 4.9 billion nematodes per hectare. At this relatively high concentration we reduced survival by $35 \%$. At our highest dose, which was equivalent to 39.5 billion/ha, we achieved $75 \%$ mortality over a 10 -d period. Given current techniques for mass rearing of entomopathogenic nematodes, using such high concentrations in an inundative release program would be prohibitively expensive.

The interaction between $H$. bacteriophora and phylloxera survival was dependent on soil moisture (Fig. 3 ). Only at water contents above $13 \%$ did we see a significant reduction in survivorship. This result is consistent with other research on pathogenicity of entomopathogenic nematodes (Shetlar et al. 1988, Yeh and Alm 1992, Koppenhofer et al. 1995, Grant and Villani 1998). One way to potentially overcome this constraint is to use a trickle irrigation system to deliver nematodes to the root zone. This technique has shown some promise when targeted against pests such as black vine weevil, Otiorhynchus sulcatus (F.), in strawberries, Fragaria $\times$ ananassa Duchesne (Curran 1992, Kakouli-Duarte et al. 1997) and may allow conservation of endemic nematodes as well as those released into the system.

Many of the attached grape phylloxera that were exposed to nematodes turned a black or brick-red color after death. We never observed this color change for phylloxera in control treatments. Hence, this suggests the infective nematodes were able to successfully penetrate the phylloxera. The penetration itself may have caused death in some cases. In addition, in other hosts this color change indicates the activity of a mutualistic bacteria released by the nematodes (Kaya and Gaugler 1993). Despite being able to colonize phylloxera, we found no evidence that $H$. bacteriophora is capable of completing development and producing a new generation of infective juveniles. Phylloxera, because of its small size relative to $H$. 
bacteriophora, may simply not provide the nematodes sufficient resources to complete development. Determining the mechanisms by which $H$. bacteriophora kills phylloxera, however, may provide insights into new approaches for controlling phylloxera, such as the identification and cloning of genes from symbiotic bacteria that code for phylloxera-active proteins.

In summary, although $H$. bacteriophora is capable of infecting and killing phylloxera under laboratory conditions, a number of constraints exist that limit its usefulness as a biological control agent against grape phylloxera in vineyards. Chief among these are their sensitivity to soil moisture and lack of reproduction in the host and the need to use very high release concentrations of nematodes. Given that we only evaluated 2 strains of entomopathogenic nematodes, it is premature to completely rule out this approach to the control of grape phylloxera. Little effort has gone into understanding the factors that regulate phylloxera in its native range in vineyard settings or in native grape habitat. Efforts in this direction may lead to the identification of other candidate biological control agents.

\section{Acknowledgments}

We thank Carol Marion and Todd Ugine for assistance with laboratory bioassays, maintaining grape phylloxera colonies, and graphics. Tom Burr and Columbia Crest Vineyards provided us with phylloxera-free Cabernet Sauvignon roots for which we are grateful. Comments from J. Granett and an anonymous reviewer improved the manuscript. This research was supported through a grant from USDA CSREES Viticulture Consortium.

\section{References Cited}

Curran, J. 1992. Influence of application method and pest population size on the field efficacy of entomophathogenic nematodes. J. Nematol. 24: 631-636.

De Benedicts, J. A., and J. Granett. 1992. Variability of responses of grape phylloxera (Homoptera: Phylloxeridae) to bioassays that discriminate between California biotypes. J. Econ. Entomol. 85: 1527-1534.

Fergusson-Kolmes, L. A., and T. J. Dennehy. 1993. Differences in host utilization by populations of North American grape phylloxera (Homoptera: Phylloxeridae). J. Econ. Entomol. 86: 1502-1511.

Gaugler, R. 1988. Ecological considerations in the biological control of soil-inhabiting insect pests with entomopathogenic nematodes. Agric. Ecosyst. Environ. 24: 351-360.

Gaugler, R., and H. Kaya [eds.]. 1990. Entomopathogenic nematodes in biological control. CRC, Boca Raton, FL.

Georgis, R., and R. Gaugler. 1991. Predictability in biological control using entomopathogenic nematodes. J. Econ. Entomol. 84: 713-720.

Granett, J., P. Timper, and L. A. Lider. 1985. Grape phylloxera Daktulosphaira vitifoliae (Homoptera: Phylloxeridae) biotypes in California. J. Econ. Entomol. 78: 1463-1467.

Grant, J. A., and M. G. Villani. 1999. Moisture effects on entomopathogenic nematodes, pp. 137-143. In Proceed- ings, Fourth International Workshop on Microbial Control of Soil Dwelling Pests. AgResearch, Lincoln, New Zealand.

Kakouli-Duarte, T., L. Labuschagne, and N.G.M. Hague. 1997. Biological control of the black vine weevil, Otiorhynchus sulcatus (Coleoptera: Curculionidae) with entomopathogenic nematodes (Nematoda: Rhabditida). Ann. Appl. Biol. 131: 11-27.

Kaya, H. K. 1990. Soil ecology, pp. 189-198. In R. Gaugler and K. Kaya [eds.], Entomopathogenic nematodes in biological control. CRC, Boca Raton, FL.

Kaya, H. K., and R. Gaugler. 1993. Entomopathogenic nematodes. Annu. Rev. Entomol. 38: 181-206.

King, P. D., and G. Rilling. 1985. Variations in the galling reaction of grapevines: evidence of phylloxera biotypes and clonal reaction to phylloxera. Vitis 24: 32-42.

Koppenhofer, A. M., H. K. Kaya, and S. P. Taormino. 1995. Infectivity of entomopathogenic nematodes (Rhabditida: Steinernematidae) at different soil depths and moistures. J. Invertebr. Pathol. 65: 193-199.

Riley, C. V. 1874. Sixth annual report on the noxious, beneficial, and other insects of the state of Missouri, pp. 31-85. State Board of Agriculture of the State of Missouri. Regan and Carter, Jefferson City, MO.

SAS Institute. 1995. JMP statistics and graphics guide, version 3:1. SAS Institute, Cary, NC.

Schroeder, P., Villani, M. G., and J. P. Nyrop. 1993. Behavioral interactions of entomogenous nematodes and scarab grubs in turfgrass/soil mesocosms. J. Environ. Entomol. 22: 595-600.

Shetlar, D. J., P. E. Suleman, and R. Georgis. 1988. Irrigation and use of entomogenous nematodes, Neoaplectana spp. and Heterorhabditis heliothidis (Rhabditida: Steinerematidae and Heterorhabditidae), for control of Japanese beetle (Coleoptera: Scarabaeidae) grubs in turfgrass. J. Econ. Entomol. 81: 1318-1322.

Song, G. C., and J. Granett. 1990. Grape phylloxera (Homoptera: Phylloxeridae) biotypes in France. J. Econ. Entomol. 83: 489-493.

Villani, M. G., and R. J. Wright. 1988. Entomogenous nematodes as biological control agents of European chafer and Japanese beetle (Coleoptera: Scarabaeidae). J. Econ. Entomol. 81: 484-487.

Villani, M. G., and R. J. Wright. 1990. Environmental influences on soil macroarthropod behavior in agricultural systems. Annu. Rev. Entomol. 35: 249-269.

Weber, E., J. De Benedictis, R. Smit, and J. Granett. 1996. Enzone does little to improve health of phylloxera-infested vineyards. Calif. Agric. 50: 19-23.

Winkler, A. J., J. A. Cook, W. M. Kliewer, and L. A. Lider. 1974. General viticulture. University of California Press, Berkeley.

Woodring, J., and H. K. Kaya. 1988. Steinernematid and heterorhabditid nematodes: A handbook of biology and techniques. Southern Cooperative Series Bulletin 331. Arkansas Agricultural Experiment Station, Fayetteville, AR.

Yeh, T., and S. R. Alm. 1992. Effects of entomopathogenic nematode species, rate, soil moisture, and bacteria on control of Japanese beetle (Coleoptera: Scarabaeidae) larvae in the laboratory. J. Econ. Entomol. 85: 2144-2148.
Received for publication 1 October 1998; accepted 3 May 